\title{
Spinal cord stimulation for recurrent tethered cord syndrome in a pediatric patient: case report
}

\author{
Rachana Tyagi, MD, ${ }^{1}$ Carolyn Kloepping, MD, ${ }^{2}$ and Shruti Shah, MD² \\ Departments of ${ }^{1}$ Surgery and ${ }^{2}$ Anesthesia, Rutgers-Robert Wood Johnson Medical School, New Brunswick, New Jersey \\ The authors present a patient with a lipomyelomeningocele and worsening back pain due to recurrent tethered cord \\ syndrome. Because of the increased risk and unlikely improvement in symptoms with repeated surgical untethering, she \\ was offered an alternative treatment with a trial of dorsal spinal cord stimulation. She had an excellent response to the \\ percutaneous trial, and a permanent implant was placed, with good initial results. The authors review her case as well as \\ the treatment options, indications, and outcomes for recurrent tethered cord syndrome.
}

http://thejns.org/doi/abs/10.3171/2015.12.PEDS14645

KEY WORDS lipomyelomeningocele; recurrent tethered cord; spinal cord stimulator; neuropathic pain; spine

$\mathrm{P}$ ATIENTS with tethered cords, particularly those with a lipomyelomeningocele, are at risk for recurrent tethering after a detethering procedure. These patients often present with worsening neurological deficits, particularly pain and urological dysfunction. ${ }^{13,14}$ Once symptoms develop, repeat surgery may not provide relief, and recurrent surgeries carry increased risk of additional postoperative neurological deficit without recovery from presenting symptoms. ${ }^{11}$ Relief of pain is often the most important aspect of patient care in this population. Therefore, especially once complete incontinence has developed, repeat detethering is less beneficial due to the unlikelihood of improvement in symptoms. Spinal cord stimulation (SCS) addresses neuropathic pain without the risk of worsening neurological function due to mechanical manipulation of the neural elements, and therefore may be an appropriate treatment for patients with recurrent tethered cord. $8,30,34$

\section{Case Report}

History and Examination

We present a patient with a history of a lipomyelomeningocele and worsening back pain due to a recurrent tethered cord. The lesion was first found when the patient was 12 years old, after multiple procedures for a left foot deformity as a child. She developed new back pain and a recurrent left foot deformity at that time, and underwent her first untethering procedure at another institution. She remained stable, with only residual left foot weakness and mild deformity until the age of 19 years, when she developed recurrent back pain, urinary incontinence, and new right foot numbness and weakness. She was evaluated by a neurologist for worsening left leg numbness, and an MRI sequence was obtained, which showed a recurrent tethered cord (Fig. 1). Electromyography showed acute and chronic denervation of S-1 and S-2 on the left side, and urodynamics showed evidence of a neurogenic bladder.

\section{Operation and Postoperative Course}

The patient underwent a detethering procedure, with an incomplete resection of the tethering lesion due to extensive fibrosis around the placode/roots from the previous procedure (Fig. 2). A patulous thecal reconstruction was made with a Durepair graft. She did have increased numbness of both feet and mild worsened weakness requiring admission to an inpatient rehabilitation unit postoperatively. She developed a CSF leak that required reexploration 1 week after surgery, which was repaired without complication. After 2 months, her legs had improved sensation and strength compared with her preoperative status, but she had no improvement in bowel/bladder function, and she had worsening recurrent back pain. Flexion/extension radiographs showed no evidence of postoperative insta-

ABBREVIATIONS FBSS = failed-back surgery syndrome; SCS = spinal cord stimulation; TCS = tethered cord syndrome; VAS = visual analog scale.

SUBMITTED November 14, 2014. ACCEPTED December 7, 2015.

INCLUDE WHEN CITING Published online March 4, 2016; DOI: 10.3171/2015.12.PEDS14645. 

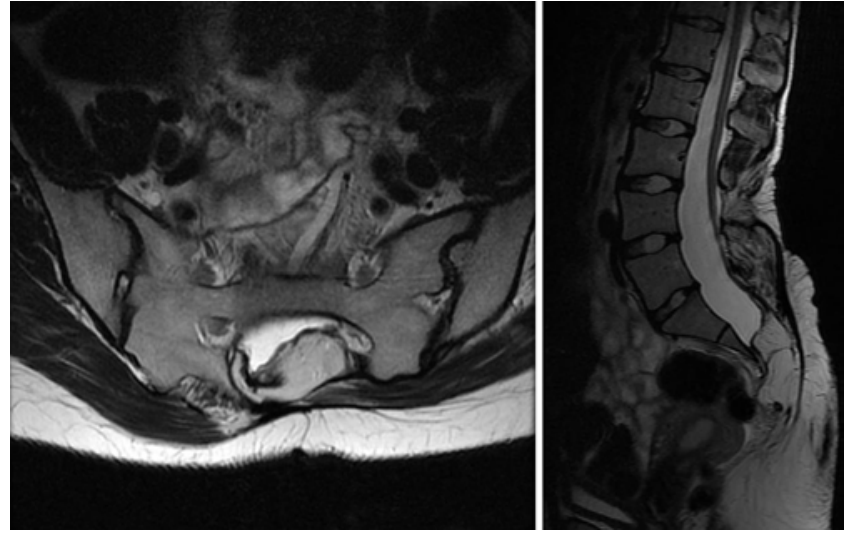

FIG. 1. Axial and sagittal T2-weighted MR images showing a lipomyelomeningocele asymmetrical to the left, with tethering of the spinal cord to the dorsal aspect of the thecal sac.

bility (Fig. 3). She progressed over the next month, with new development of a right foot deformity and worsening pain and numbness in both lower extremities, and recurrent tethered cord syndrome (TCS) was diagnosed. The significant risks of additional neurological deficit with attempted repeat untethering, and the likely failure of longterm improvement, were discussed with the patient and her family.

\section{Pain Evaluation, Nonsurgical Treatments, and Outcomes}

Because the most disabling symptoms were her back and leg pain, the patient was referred to the pain management service. During their evaluation, she reported constant burning pain with radiation into the legs bilaterally, visual analog scale (VAS) Score 8-9/10. The patient experienced associated allodynia and hyperpathia of the lower extremities in a nondermatomal pattern. Because the symptoms were consistent with neurogenic pain, a conservative approach was attempted, with medical management including NSAIDs, neurontin, Cymbalta, and Percocet, along with physical therapy including a Transcutaneous Electrical Nerve Stimulation (TENS) unit, with minimal relief. Subsequently a caudal epidural steroid injection was performed with fluoroscopic guidance to avoid the risk of neurological injury with a lumbar approach, also providing minimal relief.

\section{Trial and Implantation of SCS Device, and Outcome}

Therefore a trial of SCS was offered. She underwent placement of percutaneous SCS trial leads at T-8, with significant relief (Fig. 4), and subsequently a permanent stimulator was placed (Fig. 5). Her VAS score improved from a preoperative value of 8 to a 2 at her first postoperative visit, with further improvement at her 6-week followup, to a score of 1 . She was able to ambulate without assistive devices, and returned to work at a retail clothing store. There was no improvement in her bowel or bladder function, but she was able to remain socially continent. She did have some recurrence of her pain at 10 months postimplantation, but was still significantly better than prior to surgery (Table 1). The allodynia and hyperpathia were also improved, and she was able to wear clothing and

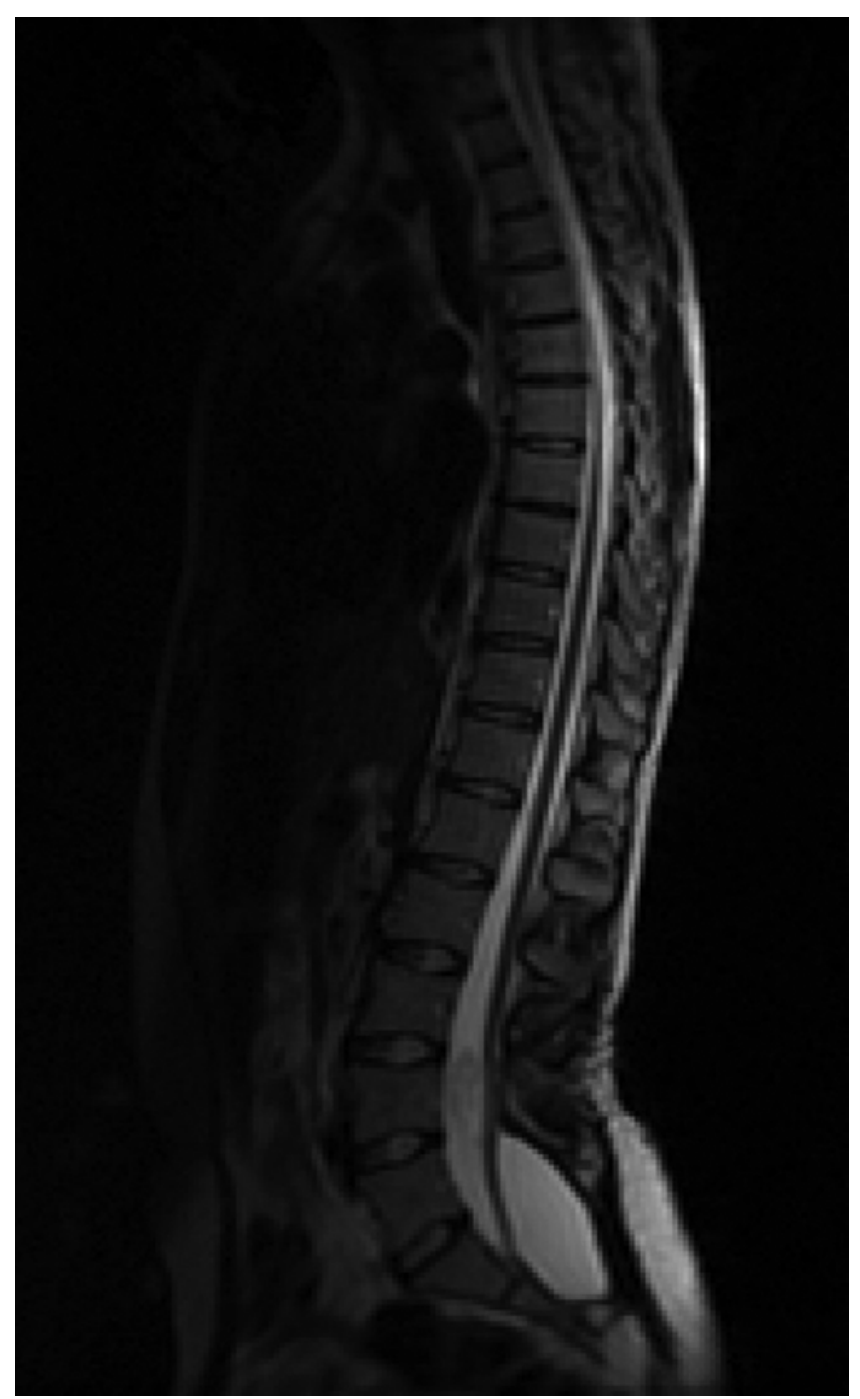

FIG. 2. Sagittal T2-weighted MR image showing patulous dural reconstruction, but with persistent tethering of the spinal cord to the sacral dura anteriorly.

shoes, perform her activities of daily living, and continue with her work.

\section{Discussion}

Tethered cord syndrome is a constellation of symptoms including any combination of back and leg pain, bowel and bladder dysfunction, scoliosis, lower-extremity weakness, atrophy, and deformity. The tethering lesion may be simply a tight filum terminale, or a form of spinal dysraphism including split cord malformations, myelomeningocele, lipomyelomeningocele, dermal sinus tract, or caudal regression syndrome. Pain is the most common presenting symptom of TCS in school-age children and adults, ${ }^{13,14} \mathrm{al}$ though it is less commonly noted in younger patients. ${ }^{4}$ This may be due to the inability of young children to articulate their pain. This pain worsens with flexion or vigorous physical activity particularly, affecting primarily the lower back, perineum, and/or the legs. Among all the symptoms, pain is the one most likely to be improved at the time of 


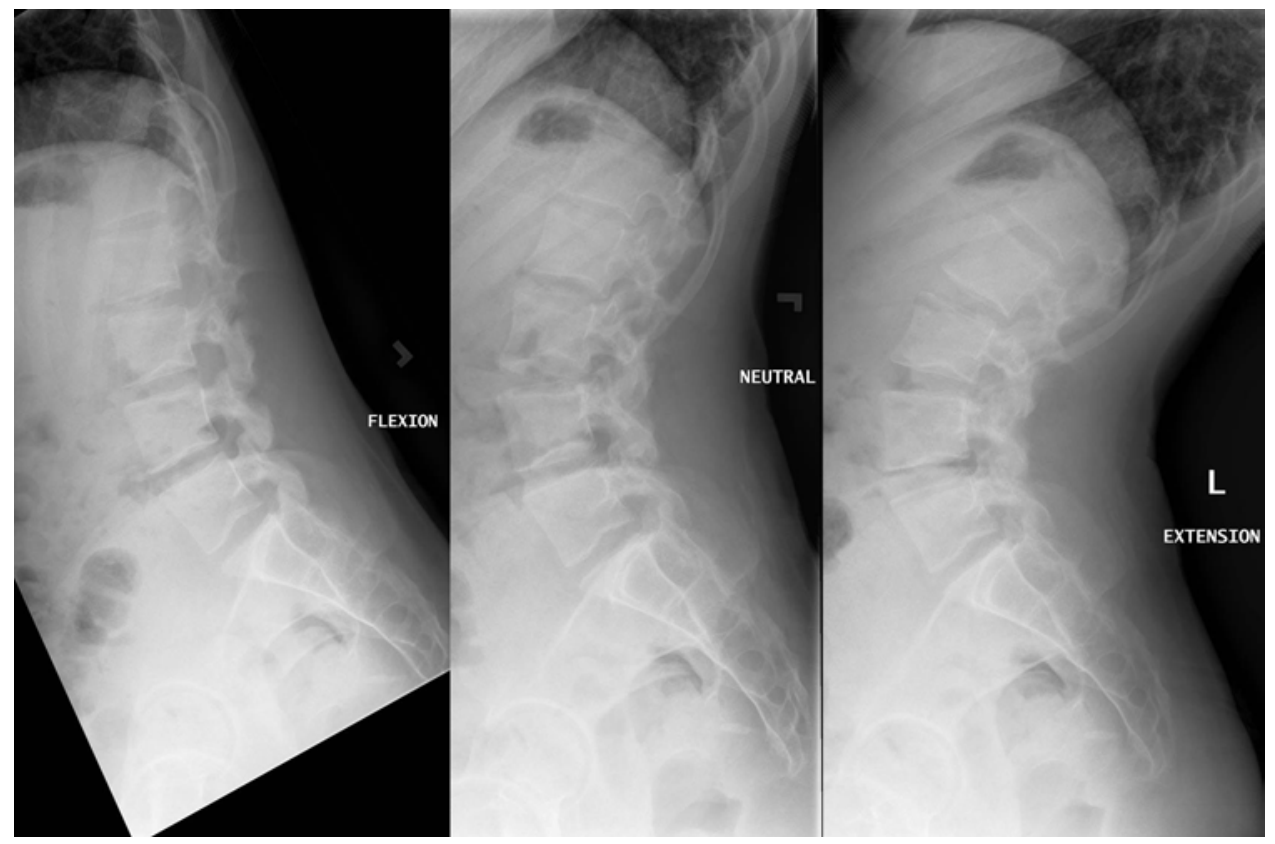

FIG. 3. Lateral flexion, neutral, and extension radiographs showing no evidence of instability as cause of recurrent back pain.

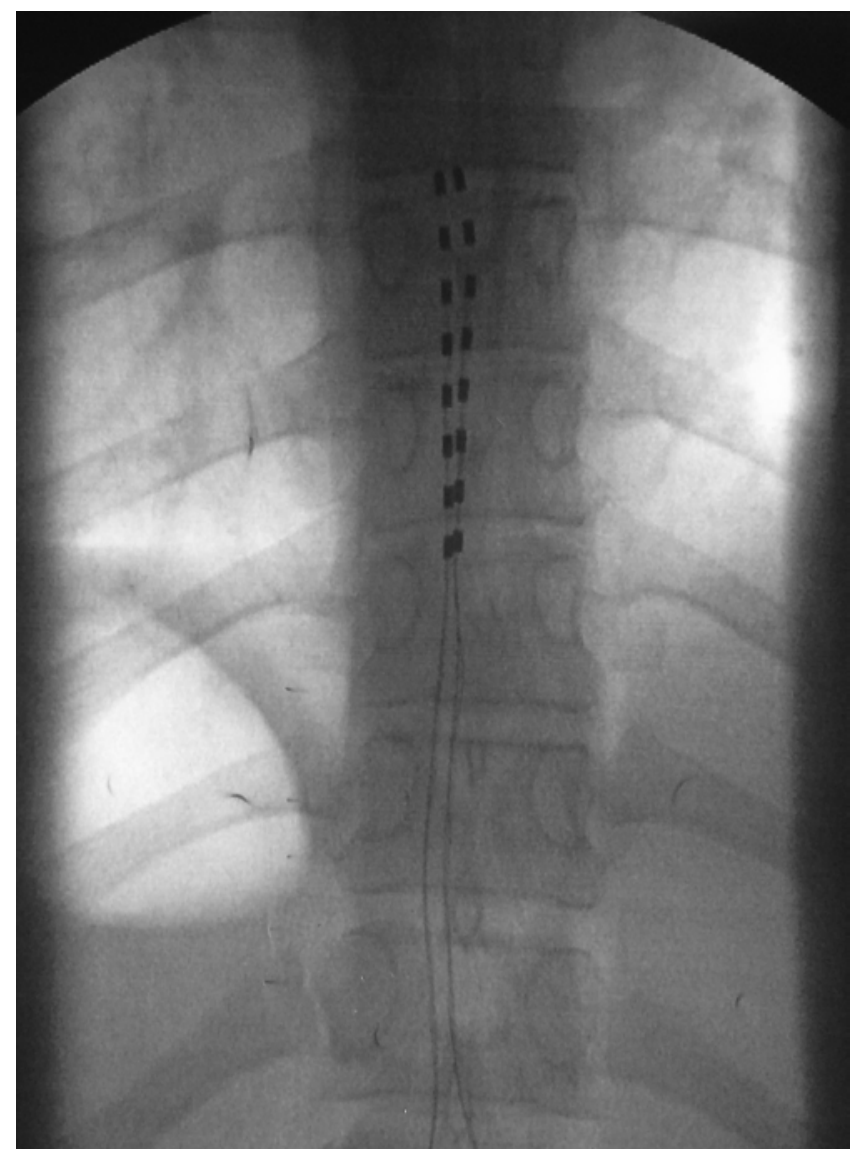

FIG. 4. Intraoperative fluoroscopic image showing placement of the temporary percutaneous SCS trial leads at T-8. initial surgery, involving a success rate of $75 \%-89 \%$ in the adult patient. ${ }^{13,18,22}$ Bladder dysfunction and orthopedic deformities are the least likely to resolve after untethering. ${ }^{14}$ Unfortunately, patients with recurrent tethering have a much poorer prognosis, with most developing permanent neurological deficits and intractable pain. ${ }^{18}$

Spinal cord untethering specifically for lipomyelomeningocele is a well-accepted procedure, with current recommendations for untethering prior to symptom onset in the hopes of preventing or delaying neurological deterioration, which may include back and/or leg pain, weakness, numbness, paresthesias, and incontinence. ${ }^{2,11}$ Once neurological deficits develop, secondary abnormalities including atrophy, limb deformity, and scoliosis may also progress to chronic problems requiring further surgical intervention. Unfortunately surgical intervention, even prior to the onset of deficits, does not guarantee longterm success, and treatment after the onset of symptoms is associated with higher rates of permanent neurological deficits. ${ }^{2,6,14}$ This is particularly true of patients with an asymmetrical tethering, as in our patient. ${ }^{6,11}$ Despite surgery, many patients will show progressive deterioration over time, and often require repeated procedures. Deterioration is thought to be due to multiple factors, including mechanical tension on neural elements, and ischemia due to hypoperfusion of the cord. ${ }^{36}$ The success of subsequent surgeries diminishes in adult patients, with poor pain relief, partial recovery or stabilization of motor and sensory deficits, and the unlikelihood of improvement in bladder dysfunction. The risk of retethering also increases after an episode of recurrent tethering, leading to a no-win situation for these patients with complicated cases. ${ }^{11}$

An alternative method to reduce traction on the neural elements without detethering is to shorten the spine by performing a vertebrectomy. This has been described as 


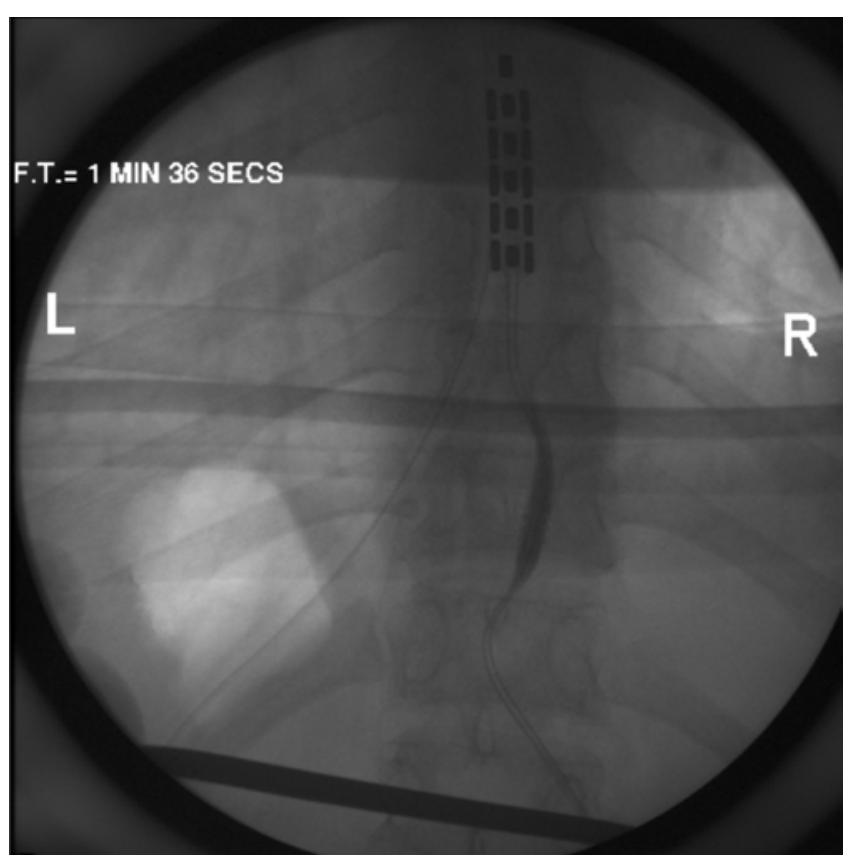

FIG. 5. Intraoperative fluoroscopic image showing placement of the permanent implant stimulator leads at T-8. F.T. = fluoroscopy time.

a useful technique to prevent further neurological deficit when correction of a deformity or anterior decompression is indicated. 1,3,5,12,16,27,28,37 Congenital deformities may be secondary to a primary tethered cord (usually a myelomeningocele with a gibbus), and good success has been noted in these cases. ${ }^{12,16,28}$ Primary spine shortening to treat recurrent tethered cord symptoms in patients without a spinal deformity would theoretically be possible, but would be significantly more invasive, with a higher risk of complications than the SCS procedure that we chose.

\section{Mechanism of SCS Specific to TCS}

Complex postoperative pain syndromes are difficult to treat with pharmacological and interventional pain treatments. One of the more invasive but effective treatments for chronic neuropathic pain is dorsal SCS. This technique delivers mild electrical signals to the epidural space just posterior to the spinal cord through one or more thin wires, called leads. An initial percutaneous trial is performed with leads connected to an external pulse generator that the patient carries for a few days to determine if the stimulation provides adequate relief, and no significant side ef-

TABLE 1. The VAS scores in patients with TCS at different time points during treatment

\begin{tabular}{lc}
\hline Treatment Stage & VAS Score \\
\hline Preimplant & $8 / 10$ \\
\hline Trial implant & $2 / 10$ \\
\hline Permanent implant & $2 / 10$ \\
\hline 6 wks postimplant & $1 / 10$ \\
\hline 6 mos postimplant & $1-2 / 10$ \\
\hline 10 mos postimplant & $4 / 10$ \\
\hline
\end{tabular}

fects. If the treatment is effective, a permanent internal system is then implanted. A stimulator paddle passed to the same level as the trial leads is used, and the extension wire is tunneled subcutaneously to a distal pocket created for the pulse generator (Fig. 6). The neurostimulation from the electric signal causes paresthesia in the area of chronic pain. Anatomical changes in the spinal cord, for example TCS, may influence the exact level and location of electrode implantation.

The effectiveness of SCS in patients with chronic intractable neuropathic pain is well known and has been comprehensively described. ${ }^{8}$ Intraoperative stimulation is the cornerstone of any successful procedure; patients should be able to perceive stimulation in the same areas where they feel pain. Therefore, patients must be awake, feel comfortable without any pain, and be fully cooperative to report this to the implant team during the placement of electrodes..$^{8,23}$

The gate control theory proposed by Melzack theorized that the balance between large and small fibers in the dorsal horn of the spinal cord played a major role in the perception of pain. ${ }^{25}$ This theory was the major foundation for the development of SCS. It was proposed that by stimulating A-beta fibers through neuromodulation, less pain signaling would be perceived by the patient. ${ }^{20,23}$ In a review article by Linderoth and Foreman, ${ }^{24}$ they proposed that the reduction of neuropathic pain from SCS results from inhibition of the dorsal horn's wide dynamic range neurons.

More recently, other theories of SCS modulation of pain control have been proposed; SCS has been involved in decreasing the responsiveness of wide dynamic range cells in the dorsal horn of the spinal cord to peripheral stimuli. ${ }^{7}$ Furthermore, SCS may produce enhanced release

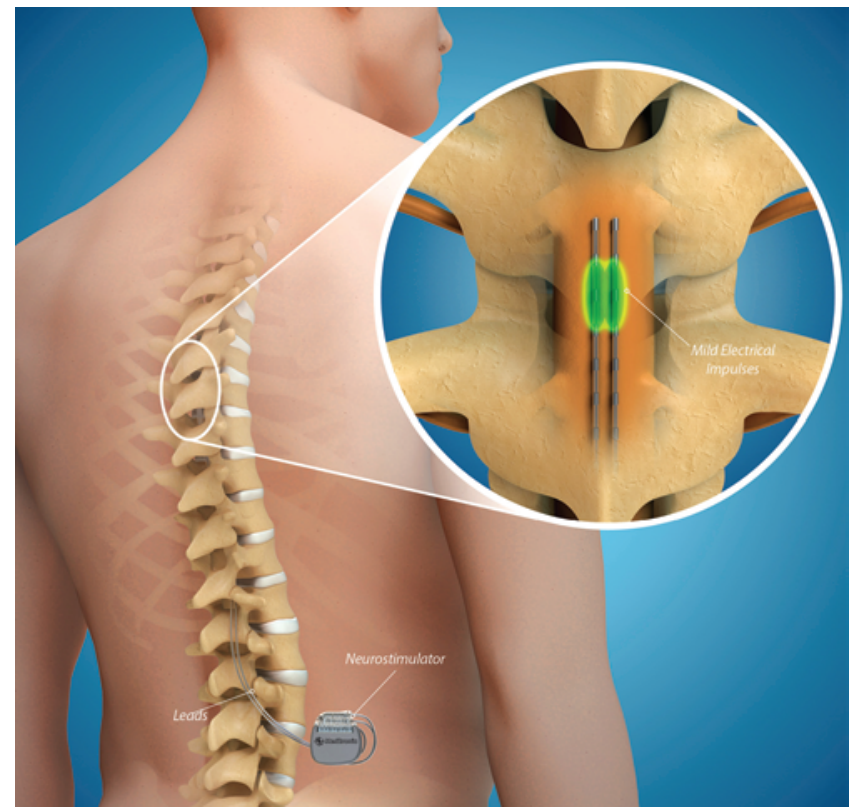

FIG. 6. Illustration of implanted SCS device with leads at T-9, with extension wire tunneled to the pulse generator located in the right gluteal subcutaneous pocket. Reprinted with the permission of Medtronic, Inc. (C2011. Figure is available in color online only. 
of $\gamma$-aminobutyric acid and decreased release of glutamate at the dorsal horn, both contributing to decreased modulation of pain perception. Acetylcholine has also been shown to be released with SCS and is associated with activation of the muscarinic M4 receptor. ${ }^{7}$ In a review by $\mathrm{Wu}$ et al. in 2008, a spinal cord stimulator was shown to produce antidromic activation of sensory fibers and decreased sympathetic outflow as well as an increase in vasomotor center activity and release of neurohumoral factors when placed in patients with vascular disease. ${ }^{35}$

\section{Indications for SCS}

The US FDA currently approves SCS for chronic pain from failed-back surgery syndrome (FBSS), intractable low-back pain, and chronic pain of the trunk and limbs.? The SCS technique has been used for the treatment of various conditions, including complex regional pain syndrome, ${ }^{32,34} \mathrm{FBSS},{ }^{31,34}$ peripheral vascular disease, ${ }^{10}$ neuropathic pain, ${ }^{33}$ refractory angina, ${ }^{10}$ and more recently, visceral pain, ${ }^{17}$ including pelvic pain. ${ }^{15}$ Outcome research has shown that SCS for FBSS is effective to improve quality of life, increase activities of daily living, ${ }^{21}$ and reduce health care costs for the long run.

Failed-back surgery syndrome, also known as postlaminectomy syndrome, is chronic intractable back and/or leg pain that results in varying degrees of functional status limitation after spinal surgery ${ }^{19}$ Relevant to FBSS, the percentage of patients who report significant pain relief after a single-level fusion ranges from $40 \%$ to $80 \%$, whereas after a 3-level fusion the percentage drops to $15 \% .{ }^{9}$ Krames et al. concluded that SCS for the chronic pain of FBSS may be more cost-effective, safer, and more appropriate than repeat surgery. ${ }^{19}$ In regard to pain suppression, SCS was more effective than reoperation in randomized controlled trials..$^{29}$ In the PROCESS (Prospective Randomized Controlled Multicenter Trial of the Effectiveness of Spinal Cord Stimulation) report published by Kumar et al. in $2008,{ }^{21}$ wherein patients were randomized to either SCS or conventional medical management for FBSS, 42 of 52 patients randomized to SCS reported significant relief of leg pain and an improved quality of life at 6 months. Additionally, of the patients randomized to medical management, after 6 months, 30 of the 44 patients crossed over to the SCS treatment arm; at 24 months, the addition of SCS to conservative management continued to provide additional pain relief compared with conservative management alone.

The case study presented by Moens et al. ${ }^{26}$ showed benefit from SCS in adults with chronic pain secondary to tethered cord. In our case we were also able to obtain significant pain coverage. However, we used 2 epidural leads placed at T-8. In the study by Moens et al., they reported successful paresthesia coverage with leads placed much lower in the vertebral column (T-12).

\section{Conclusions}

Recurrent TCS causes severe disability in patients, with often severe neuropathic pain. Dorsal SCS is an effective treatment in patients with other etiologies of chronic neuropathic pain. Patients with a lipomyelomeningocele are at particularly high risk for recurrent tethering, with pro- gression of symptoms and worsening neurological deficits after attempts at repeat surgical detethering.

Despite the anatomical abnormality of the spinal cord in TCS, neuromodulation is an effective therapeutic option to achieve pain relief. ${ }^{26}$ The implantation of a spinal cord stimulator in a young patient with TCS as an effective treatment for refractory chronic neuropathic pain has not been described previously. In our case we had a very good short-term outcome in a young adult patient with chronic intractable neuropathic mediated pain secondary to recurrent tethered cord. Further evaluation of this technique as an alternative treatment for recurrent TCS will be required to determine long-term results and applicability in a larger pool of patients with tethered cord.

\section{References}

1. Aydogan M, Ozturk C, Tezer M, Mirzanli C, Karatoprak O, Hamzaoglu A: Posterior vertebrectomy in kyphosis, scoliosis and kyphoscoliosis due to hemivertebra. J Pediatr Orthop B 17:33-37, 2008

2. Blount JP, Elton S: Spinal lipomas. Neurosurg Focus 10(1):e3, 2001

3. Bradford DS, Tribus CB: Vertebral column resection for the treatment of rigid coronal decompensation. Spine (Phila Pa 1976) 22:1590-1599, 1997

4. Bui CJ, Tubbs RS, Oakes WJ: Tethered cord syndrome in children: a review. Neurosurg Focus 23(2):E2, 2007

5. Cho WJ, Kang CN, Park YS, Kim HJ, Cho JL: Surgical correction of fixed kyphosis. Asian Spine J 1:12-18, 2007

6. Cochrane DD: Cord untethering for lipomyelomeningocele: expectation after surgery. Neurosurg Focus 23(2):E9, 2007

7. Compton AK, Shah B, Hayek SM: Spinal cord stimulation: a review. Curr Pain Headache Rep 16:35-42, 2012

8. Cruccu G: Treatment of painful neuropathy. Curr Opin Neurol 20:531-535, 2007

9. Deyo RA, Nachemson A, Mirza SK: Spinal-fusion surgerythe case for restraint. N Engl J Med 350:722-726, 2004

10. Erdek MA, Staats PS: Spinal cord stimulation for angina pectoris and peripheral vascular disease. Anesthesiol Clin North America 21:797-804, 2003

11. Finn MA, Walker ML: Spinal lipomas: clinical spectrum, embryology, and treatment. Neurosurg Focus 23(2):E10, 2007

12. Fürderer S, Eysel P, Hopf C, Heine J: Sagittal static imbalance in myelomeningocele patients: improvement in sitting ability by partial and total gibbus resection. Eur Spine $\mathbf{J}$ 8:451-457, 1999

13. Iskandar BJ, Fulmer BB, Hadley MN, Oakes WJ: Congenital tethered spinal cord syndrome in adults. Neurosurg Focus 10(1):e7, 2001

14. Kang JK, Yoon KJ, Ha SS, Lee IW, Jeun SS, Kang SG: Surgical management and outcome of tethered cord syndrome in school-aged children, adolescents, and young adults. $\mathbf{J}$ Korean Neurosurg Soc 46:468-471, 2009

15. Kapural L, Narouze SN, Janicki TI, Mekhail N: Spinal cord stimulation is an effective treatment for the chronic intractable visceral pelvic pain. Pain Med 7:440-443, 2006

16. Karlin LI: Kyphectomy for myelodysplasia. Neurosurg Clin N Am 18:357-364, 2007

17. Khan YN, Raza SS, Khan EA: Application of spinal cord stimulation for the treatment of abdominal visceral pain syndromes: case reports. Neuromodulation 8:14-27, 2005

18. Klekamp J: Tethered cord syndrome in adults. J Neurosurg Spine 15:258-270, 2011

19. Krames ES, Monis S, Poree L, Deer T, Levy R: Using the SAFE principles when evaluating electrical stimulation 
therapies for the pain of failed back surgery syndrome. Neuromodulation 14:299-311, 2011

20. Kreis PG, Fishman SM, Chau K: Impact to spinal cord stimulator lead integrity with direct suture loop ties. Pain Med 10:495-500, 2009

21. Kumar K, Taylor RS, Jacques L, Eldabe S, Meglio M, Molet $\mathrm{J}$, et al: The effects of spinal cord stimulation in neuropathic pain are sustained: a 24-month follow-up of the prospective randomized controlled multicenter trial of the effectiveness of spinal cord stimulation. Neurosurgery 63:762-770, 2008

22. Lew SM, Kothbauer KF: Tethered cord syndrome: an updated review. Pediatr Neurosurg 43:236-248, 2007

23. Lind G, Meyerson BA, Winter J, Linderoth B: Implantation of laminotomy electrodes for spinal cord stimulation in spinal anesthesia with intraoperative dorsal column activation. Neurosurgery 53:1150-1154, 2003

24. Linderoth B, Foreman RD: Physiology of spinal cord stimulation: review and update. Neuromodulation 2:150-164, 1999

25. Melzack R: From the gate to the neuromatrix. Pain 6 (Suppl 6):S121-S126, 1999

26. Moens M, De Smedt A, D’Haese J, Droogmans S, Chaskis C: Spinal cord stimulation as a treatment for refractory neuropathic pain in tethered cord syndrome: a case report. $\mathbf{J}$ Med Case Reports 4:74, 2010

27. Murrey DB, Brigham CD, Kiebzak GM, Finger F, Chewning SJ: Transpedicular decompression and pedicle subtraction osteotomy (eggshell procedure): a retrospective review of 59 patients. Spine (Phila Pa 1976) 27:2338-2345, 2002

28. Nolden MT, Sarwark JF, Vora A, Grayhack JJ: A kyphectomy technique with reduced perioperative morbidity for myelomeningocele kyphosis. Spine (Phila Pa 1976) 27:1807-1813, 2002

29. North RB, Kidd DH, Farrokhi F, Piantadosi SA: Spinal cord stimulation versus repeated lumbosacral spine surgery for chronic pain: a randomized, controlled trial. Neurosurgery 56:98-107, 2005

30. Taylor RS: Spinal cord stimulation in complex regional pain syndrome and refractory neuropathic back and leg pain/ failed back surgery syndrome: results of a systematic review and meta-analysis. J Pain Symptom Manage 31 (4 Suppl):S13-S19, 2006

31. Taylor RS, Van Buyten JP, Buchser E: Spinal cord stimulation for chronic back and leg pain and failed back surgery syndrome: a systematic review and analysis of prognostic factors. Spine (Phila Pa 1976) 30:152-160, 2005

32. Taylor RS, Van Buyten JP, Buchser E: Spinal cord stimulation for complex regional pain syndrome: a systematic review of the clinical and cost-effectiveness literature and assessment of prognostic factors. Eur J Pain 10:91-101, 2006

33. Tesfaye S, Watt J, Benbow SJ, Pang KA, Miles J, MacFarlane IA: Electrical spinal-cord stimulation for painful diabetic peripheral neuropathy. Lancet 348:1698-1701, 1996

34. Turner JA, Loeser JD, Deyo RA, Sanders SB: Spinal cord stimulation for patients with failed back surgery syndrome or complex regional pain syndrome: a systematic review of effectiveness and complications. Pain 108:137-147, 2004

35. Wu M, Linderoth B, Foreman RD: Putative mechanisms behind effects of spinal cord stimulation on vascular diseases: a review of experimental studies. Auton Neurosci 138:9-23, 2008

36. Yamada S, Won DJ, Pezeshkpour G, Yamada BS, Yamada SM, Siddiqi J, et al: Pathophysiology of tethered cord syndrome and similar complex disorders. Neurosurg Focus 23(2):E6, 2007

37. Zarzycki D, Rymarczyk A, Bakalarek B, Kalicinski M, Winiarski A: Surgical treatment of congenital vertebral displacement Type A in the sagittal plane only: a retrospective study involving eleven cases. Spine (Phila Pa 1976) 27:72-77, 2002

\section{Disclosures}

The authors report no conflict of interest concerning the materials or methods used in this study or the findings specified in this paper.

\section{Author Contributions}

Conception and design: Tyagi, Shah. Acquisition of data: all authors. Analysis and interpretation of data: Tyagi, Shah. Drafting the article: Tyagi, Shah. Critically revising the article: Tyagi, Shah. Reviewed submitted version of manuscript: all authors. Approved the final version of the manuscript on behalf of all authors: Tyagi. Study supervision: Tyagi, Shah.

\section{Supplemental Information \\ Previous Presentations}

Portions of this work were presented in poster form at the AANS/ CNS Section of Pediatric Neurosurgery Annual Meeting, held in Toronto, Canada, on December 4, 2013.

\section{Correspondence}

Rachana Tyagi, Division of Neurosurgery, Rutgers-Robert Wood Johnson Medical School, 125 Paterson St., Ste. 2100, New Brunswick, NJ 08901.email: tyagira@rutgers.edu. 